\title{
A Study on Drug use Pattern among Paediatric In-Patients at a Tertiary Care Hospital at Gulbarga
}

\author{
Neelkantreddy Patil, Pooja Salimath*, Archana Karimungi, Manjunath Gandage, Issac Clayton, \\ Krishnakiran
}

Department of Pharmacy Practice HKES MTRIPS Mahadevappa Rampure Marg, Sedam Rd, Kalaburagi, Karnataka 585105, INDIA.

\begin{abstract}
Background: Drug use in pediatric patients is a unique dilemma in the management and monitoring of disease, as safe and effective therapeutic regimen is challenging. So drug use pattern is essential to facilitate rationale use of drugs. Objectives: To assess the drug use pattern among paediatric in-patients at a tertiary care hospital, Gulbarga using WHO prescribing indicators. Methodology: A prospective-observational study in paediatric In-patient department. Results: A total of 134 paediatric in-patients were enrolled into the study. The prescriptions included in the study were 322 for a total of 1214 encounters. The results shows, among 134 patients, number of children $(90.29 \%)$ were more than infants $(9.71 \%)$. Majority of the patients were males $(55.2 \%)$ than females $(44.77 \%)$. There were 26 patients whose weight was not mentioned. The duration of hospital stay showed that the maximum length of stay was 11 days with a minimum of 1 day stay. Among 134 patients majority of the patients were diagnosed with (RTI) respiratory tract infections (39.5\%). A total of 711 drugs were prescribed, majority of drugs were prescribed by their brand names (69.3\%) when compared to generic drugs $(30.64 \%)$.

Analysis of WHO core drug prescribing trends shows that the average number of drugs per prescription was 4.9 . and percentage of antibiotics per prescription being $19.5 \%$, percentage of injections per prescription $34.43 \%$ and percentage of drugs prescribed from (NELM) National essential list of medicines being $42 \%$. The most common route of drug administration was parentral $(57.18 \%)$ followed by oral route $(42.81 \%)$. Conclusion: From this study feedback information can be provided to the prescriber and authorities of the institute to improve the prescription pattern.
\end{abstract}

Key words: NLEM, Drug use pattern, RTI, Core prescribing indicators, Rational use of drugs.

\section{INTRODUCTION}

Paediatrics is the branch of medicine which deals with the diagnosis, treatment and prevention of diseases in children. Drug therapy becomes a major component to cure the diseases in hospitals and other health care settings. In order to provide effective therapy in pediatrics, it becomes essential to diagnose the disease accurately and provide ideal drug therapy. ${ }^{1}$

Infants and children constitute about $40 \%$ of the Indian population. Infants and children are vulnerable to non-serious illness. These diseases are circumscribed and are treated inappropriately, which results in unnecessary polypharmacy. There is a lack of research on dosing of drugs in pediatrics when compared to adults. Hence, there are very few pediatric formulations approved in market. Prescribers and consumers are flooded with wide range of pharmaceutical preparation with multiple brand names which are not affordable to many consumers. In order to overcome this issue, proper drug utilization studies becomes necessary to limit the economic burden and keep a proper vigilance on safe and effective use of drugs at every stage of the treatment, regardless of considerable improvements in the availability and controlled use of drugs in the hospitals, rational drug use becomes worldwide concern. ${ }^{2}$

The world health organization has formulated a set of core drug use indicators for the rational drug use. The core prescribing indicators measure the prescriber's performance, the patient care indicators
DOI: 10.5530/ijopp.12.1.7

Address for correspondence: Dr Pooja V Salimath, Mahadevappa Rampure Marg, Sedam Rd, Kalaburagi, Karnataka 585105, INDIA

Phone no: +919481614817 Email Id: poojasalimath91@ gmail.com

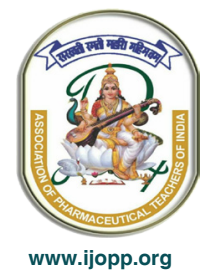


measures patient experience on health care facilities and facility indicators measures the effective performance of health care personnel. ${ }^{3}$

To foster rational drug use in developing countries, assessment of drug use patterns with WHO drug use indicators has become obligatory. ${ }^{4,5}$ Before promoting rational drug use, necessary measures should be taken to assess the possible outcomes. There are many survey methodologies available to promote rational drug use, among them WHO health facility drug use indicators are widely used. These indicators are now accepted and used by more than 30 developing countries. ${ }^{6}$

Therefore, this study was conducted in pediatrics department to assess the drug use patterns by applying WHO prescribing indicators, to get the data on demographics, percentage of drug use, route of administration, type of dosage form, usage of essential medicines. The results obtained from this study would help both the prescriber and institutional authorities to review their prescribing patterns and reconstruct it if, necessary to provide better health care services.

\section{MATERIALS AND METHODS Methodology}

A hospital based prospective observational study was conducted in Basaveshwar Teaching and general hospital, Gulbarga, by enrolling Paediatric in-patients of either sex below 12 years of age and after obtaining assent from the patients willing to participate in the study. Paediatric Patients admitted to ICU, patients suffering with HIV and Paediatric outpatients were excluded from the study.

The data for the study was collected from Case sheets of paediatric in- patients and from other relevant sources. The study was carried out after obtaining the ethical clearance from the institutional ethics committee Mahadevappa Rampure Medical College Gulbarga and with prior permission from the Head, Department of Paediatrics, Basveshwar Teaching and General Hospital.

The enrolled patient's prescription were intensively monitored during their hospital stay. All the necessary and relevant data were collected using suitably designed Patient Data Collection Form. From in-patients case sheets and treatment charts, the data like age and sex, diagnosis, type of drug, class of drug, dose, dosage form and duration were collected. The prescriptions were also assessed by using WHO prescribing indicators.

\section{RESULTS}

A total of 134 paediatric in-patients were enrolled into the study by considering the study criteria. Among them, $55.22 \%$ were males and $44.78 \%$ were females (Table 1, Graph 1). Age distribution showed that $90.29 \%$ were aged between $1-12$ years (children) and $9.71 \%$ were aged between 4 weeks - 1 year (infants) (Table 2, Graph 2). The number of days the patients stayed in hospital showed that, $29.10 \%$ patients stayed for 5 days, $19.40 \%$ patients stayed for 3 days, $12.69 \%$ patients stayed for 4 days, $8.96 \%$ patients stayed for 6 days, $8.96 \%$ patients stayed for 7 days, $7.46 \%$ patients stayed for 1 day, $5.97 \%$ patients stayed for 2 days, $3.73 \%$ patients stayed for 8 days, $2.24 \%$ patients stayed for 10 days and $1.49 \%$ patient stayed for 11 days (Table 3, Graph 3). In our study it was found that in $80.59 \%$ patients prescription weight was not mentioned and $19.41 \%$ patients prescription weight was not mentioned.

The average number of drugs per prescription was more when compared to the recommendation of WHO

\begin{tabular}{cccc}
\multicolumn{3}{c}{ Table 1: Gender Distribution of Pediatric Patients. } \\
SI no & $\begin{array}{c}\text { Gender } \\
\text { distribution }\end{array}$ & $\begin{array}{c}\text { Total no. of } \\
\text { patients } \\
\mathbf{n = 1 3 4}\end{array}$ & $\begin{array}{c}\text { \% of total no. of } \\
\text { patients }\end{array}$ \\
\hline 1 & Males & 74 & $55.22 \%$ \\
2 & Females & 60 & $44.78 \%$ \\
& Total & 134 & $100 \%$ \\
\hline
\end{tabular}

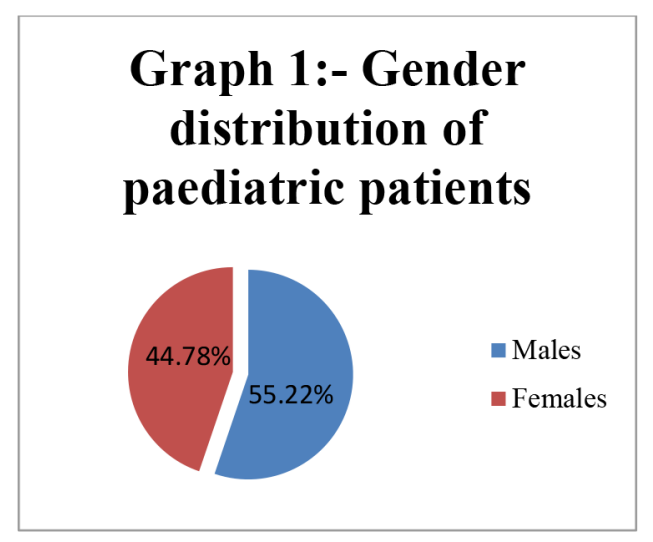

Table 2: Age distribution of paediatric patients.

\begin{tabular}{cccc}
$\begin{array}{c}\text { SI. } \\
\text { No }\end{array}$ & $\begin{array}{c}\text { Age } \\
\text { distribution }\end{array}$ & $\begin{array}{c}\text { Total no. of } \\
\text { patients } \\
\mathbf{n = 1 3 4}\end{array}$ & $\begin{array}{c}\text { \% of total no. of } \\
\text { patients }\end{array}$ \\
\hline 1 & Infants & 13 & $9.71 \%$ \\
2 & Children & 121 & $90.29 \%$ \\
& Total & 134 & $100 \%$ \\
\hline
\end{tabular}




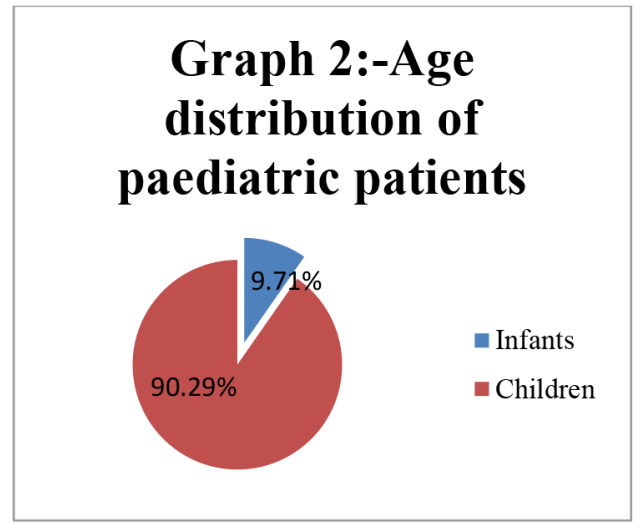

\begin{tabular}{cccc}
\multicolumn{4}{c}{ Table 3: Duration of hospital stay. } \\
\hline SI. & $\begin{array}{c}\text { No of days patient } \\
\text { stayed in hospital }\end{array}$ & $\begin{array}{c}\text { Total } \text { no. } \\
\text { of } \\
\text { patients } \\
\mathbf{n = 1 3 4}\end{array}$ & $\begin{array}{c}\text { \% of patients } \\
\text { stayed }\end{array}$ \\
\hline 1 & 5 & 39 & $29.10 \%$ \\
2 & 3 & 27 & $20.14 \%$ \\
3 & 4 & 17 & $12.69 \%$ \\
4 & 6 & 12 & $8.96 \%$ \\
5 & 7 & 12 & $8.96 \%$ \\
6 & 1 & 10 & $7.46 \%$ \\
7 & 2 & 8 & $5.97 \%$ \\
8 & 8 & 5 & $3.73 \%$ \\
9 & 10 & 3 & $2.24 \%$ \\
10 & 11 & 1 & $0.75 \%$ \\
& Total & 134 & $100 \%$ \\
\hline
\end{tabular}

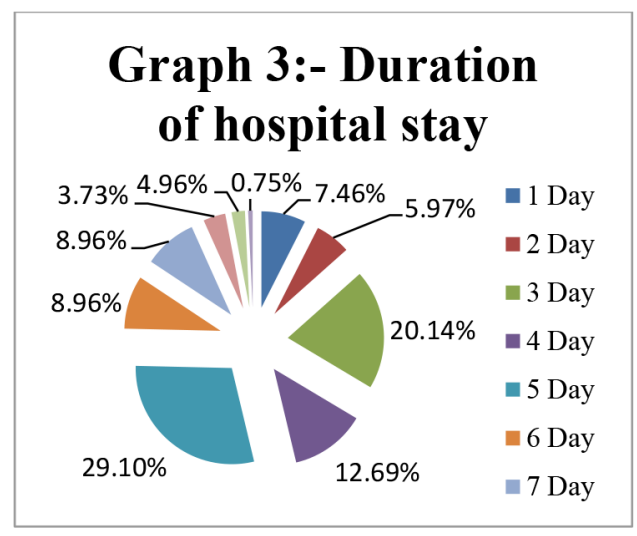

(1.6-1.8\%). Polypharmacy can unnecessarily increase the cost of treatment and put an additional burden on already exhausted health-care system. Polypharmacy has been reported to be the one of the causes of ADRs in children, which can further add to the cost of therapy.

In a nutshell, at the study site the irrational use of drug was observed, hence our study suggests that strategies to control the irrational use of drugs should be implemented and the guidelines for the treatment of paediatrics patients should be framed and implemented. In this regard the pharmacist can play a vital role by educating the prescribers to promote the rational use of drug.

In the study it was found that, in $80.59 \%$ patient's prescription weight was mentioned and $19.41 \%$ patients prescription weight was not mentioned (Table 4, Graph 4). Our study shows that, $34.32 \%$ patients were diagnosed with RTI (Respiratory Tract Infection) followed by $17.91 \%$ with gastrointestinal disorders, $13.44 \%$ with fever, $11.19 \%$ with hematological disorders, $5.97 \%$ with Central nervous system (CNS) disorders, $4.47 \%$ with Protein energy malnutrition (PEM), 2.29\% with UTI, 2.29\% with septicemia, $2.24 \%$ with renal disorders, $1.49 \%$ with poisoning conditions and $2.29 \%$ with other disorders (Table 5, Graph 5). Among 134 patients enrolled in the study there were 711 drugs prescribed among them $39.52 \%$ were antibiotics followed by $17.51 \%$ were multivitamins and minerals, $11.81 \%$ were electrolytes, $11.25 \%$ were antipyretics and analgesics, $9.14 \%$ were antacids, $8.53 \%$ were bronchodilators, antitussives and expectorants, $1.40 \%$ were antiprotozoals, $0.84 \%$ were other class of drugs. (Table 6, Graph 6).

Among 281 antibiotics prescribed there were 32.74\% cephalosporins, followed by $28.46 \%$ penicillins, $24.55 \%$ aminoglycosides, $3.95 \%$ fluoroquinolones, $3.55 \%$ antiprotozoals, $3.55 \%$ macrolides and $3.20 \%$ other antibiotics (Table 7, Graph 7). Among 711 drugs prescribed $57.88 \%$ were prescribed in parentral route, followed by $42.82 \%$ in oral route (Table 8 , Graph 8 ). Among 711 drugs prescribed, 69.36\% drugs were prescribed by brand name, $30.64 \%$ drugs were prescribed by generic name. (Table 9, Graph 9) 69.76\% drugs were prescribed from NLEM for paediatrics (April 2013) (Table 10, Graph 10).

The prescriptions were analysed by using WHO prescribing indicators and it was found that, For 134 patients enrolled in the study there were 711 drugs prescribed by 1214 encounters with an average of 4.98 drugs prescribed per encounter. The total number of encounters with an antibiotic prescribed was 1155 and the percentage of encounters with an antibiotic prescribed is $95.14 \%$. The total number of encounters with an injection prescribed was 1092 and the percentage of encounters with an injection prescribed was $89.95 \%$.

\section{DISCUSSION}

Primarily, the study has been taken up to assess the Indian Journal of Pharmacy Practice, Vol 12, Issue 1, Jan-Mar, 2019 


\begin{tabular}{cccc}
\multicolumn{4}{|c|}{ Table 4: Weight of paediatric patients. } \\
\hline $\begin{array}{c}\text { SI. } \\
\text { No }\end{array}$ & Weight of patients & $\begin{array}{c}\text { Total no of } \\
\text { patients } \\
\boldsymbol{n = 1 3 4}\end{array}$ & $\begin{array}{c}\text { \% total no. of } \\
\text { the patients }\end{array}$ \\
\hline 1 & Mentioned & 108 & $80.59 \%$ \\
2 & Not mentioned & 26 & $19.41 \%$ \\
& Total & 134 & $100 \%$ \\
\hline
\end{tabular}

\begin{tabular}{|c|c|c|c|}
\hline $\begin{array}{l}\text { SI. } \\
\text { No }\end{array}$ & Principal diagnosis & $\begin{array}{c}\text { Total no. of } \\
\text { patients } \\
n=134\end{array}$ & $\begin{array}{l}\% \text { of the no. } \\
\text { of patients }\end{array}$ \\
\hline 1 & $\begin{array}{l}\text { Respiratory tract } \\
\text { infections }\end{array}$ & 46 & $34.32 \%$ \\
\hline 2 & $\begin{array}{l}\text { Gastrointestinal } \\
\text { disorders }\end{array}$ & 24 & $17.91 \%$ \\
\hline 3 & Fever & 18 & $13.44 \%$ \\
\hline 4 & $\begin{array}{l}\text { Haematological } \\
\text { disorders }\end{array}$ & 15 & $11.19 \%$ \\
\hline 5 & CNS disorders & 10 & $7.46 \%$ \\
\hline 6 & $\begin{array}{l}\text { Protein energy } \\
\text { malnutrition }\end{array}$ & 6 & $4.48 \%$ \\
\hline 7 & Urinary tract infection & 4 & $2.99 \%$ \\
\hline 8 & Septicemia & 4 & $2.99 \%$ \\
\hline 9 & Renal disorders & 3 & $2.24 \%$ \\
\hline 10 & Poisoning & 2 & $1.49 \%$ \\
\hline \multirow[t]{2}{*}{11} & Others & 2 & $1.49 \%$ \\
\hline & Total & 134 & $100 \%$ \\
\hline
\end{tabular}

\section{Table 6: Therapeutic class of drugs prescribed.}

\begin{tabular}{cccc}
$\begin{array}{c}\text { SI. } \\
\text { No }\end{array}$ & Therapeutic class of drugs & $\begin{array}{c}\text { Total no. } \\
\text { of drugs } \\
n=711\end{array}$ & $\begin{array}{c}\% \text { of total } \\
\text { no. of } \\
\text { drugs }\end{array}$ \\
\hline 1 & Antibotics & 281 & $39.52 \%$ \\
2 & Multivitamins and minerals & 125 & $17.51 \%$ \\
3 & Electrolytes & 84 & $11.81 \%$ \\
4 & Antipyretics and Analgesics & 80 & $11.25 \%$ \\
5 & Antacids & 65 & $9.14 \%$ \\
6 & Bronchodilators, Anti-tussives, & 60 & $8.53 \%$ \\
7 & Expectorants. & 10 & $1.40 \%$ \\
8 & Antiprotozoals & 6 & $0.84 \%$ \\
& Others & 711 & $100 \%$ \\
\hline
\end{tabular}

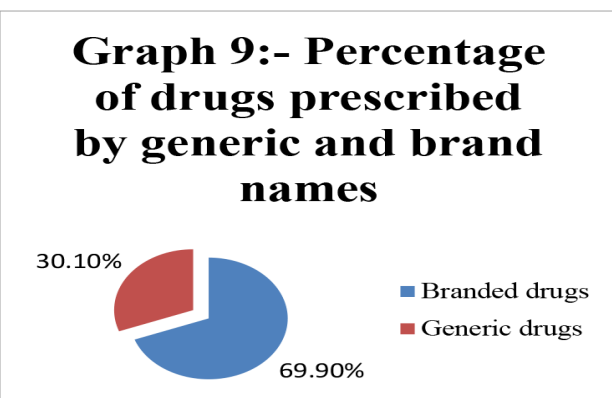

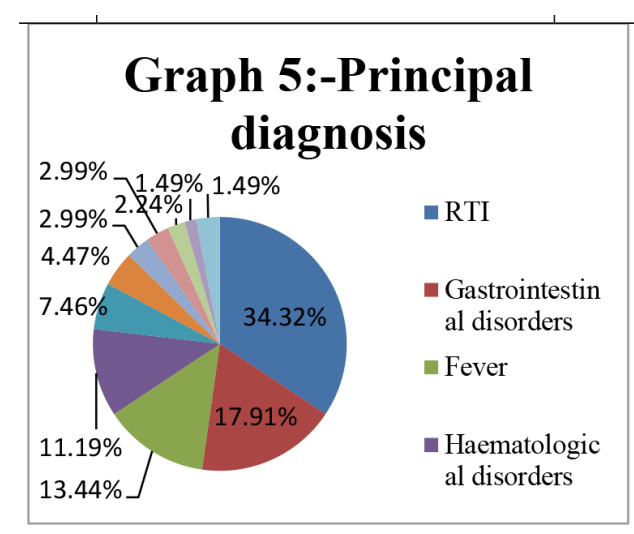
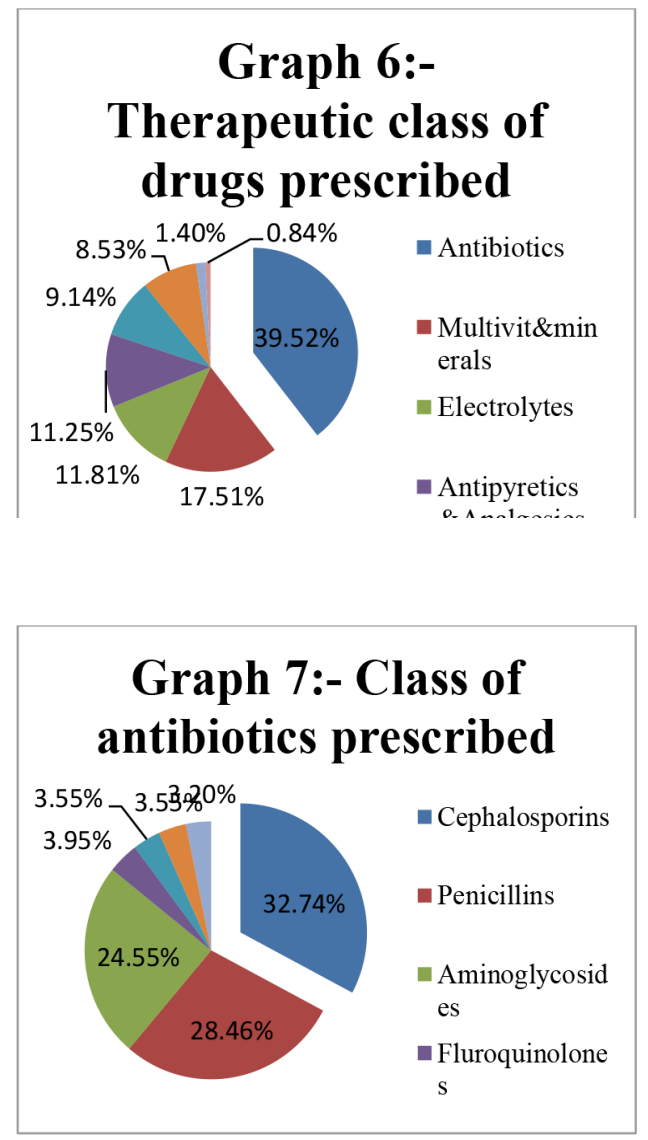

\section{Table 7: Class of antibiotics prescribed.}

\begin{tabular}{cccc}
$\begin{array}{c}\text { SI. } \\
\text { No }\end{array}$ & $\begin{array}{c}\text { Antibiotics class of } \\
\text { drug }\end{array}$ & $\begin{array}{c}\text { Total no. of } \\
\text { drugs } \\
n=281\end{array}$ & $\begin{array}{c}\% \text { of total no. of } \\
\text { drugs }\end{array}$ \\
\hline 1 & Cephalosporins & 92 & $32.74 \%$ \\
2 & Penicillins & 80 & $28.46 \%$ \\
3 & Aminoglycosides & 69 & $24.55 \%$ \\
4 & Fluroquinolones & 11 & $3.95 \%$ \\
5. & Antiprotozoals & 10 & $3.55 \%$ \\
6. & Macrolides & 10 & $3.55 \%$ \\
7. & Others & 9 & $3.20 \%$ \\
& Total & 281 & $100 \%$ \\
\hline
\end{tabular}




\section{Table 8: Route of administration of prescribed drugs.}

\begin{tabular}{cccc}
$\begin{array}{c}\text { SI. } \\
\text { No }\end{array}$ & $\begin{array}{c}\text { Route of } \\
\text { administration }\end{array}$ & $\begin{array}{c}\text { Total no of } \\
\text { drugs } \\
n=711\end{array}$ & $\begin{array}{c}\text { \% of total } \\
\text { no of drugs }\end{array}$ \\
\hline 1 & Parentral & 408 & $57.38 \%$ \\
2 & Oral & 303 & $42.62 \%$ \\
& Total & 711 & $100 \%$ \\
\hline
\end{tabular}

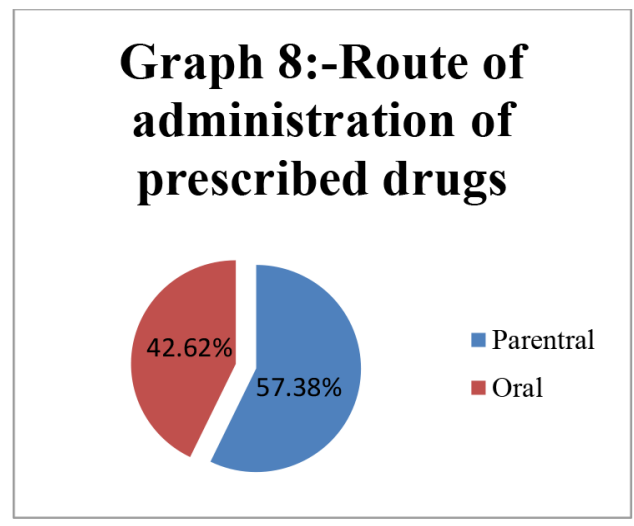

Table 9: Percentage of drugs prescribed by generic and brand names.

\begin{tabular}{cccc}
$\begin{array}{c}\text { SI. } \\
\text { No }\end{array}$ & Drugs prescribed By & $\begin{array}{c}\text { Total no. of } \\
\text { drugs } \\
n=711\end{array}$ & $\begin{array}{c}\text { \% of total } \\
\text { no. of drugs }\end{array}$ \\
\hline 1 & Brand Name & 497 & $69.90 \%$ \\
2 & Generic Name & 214 & $30.10 \%$ \\
& Total & 711 & 100 \\
\hline
\end{tabular}

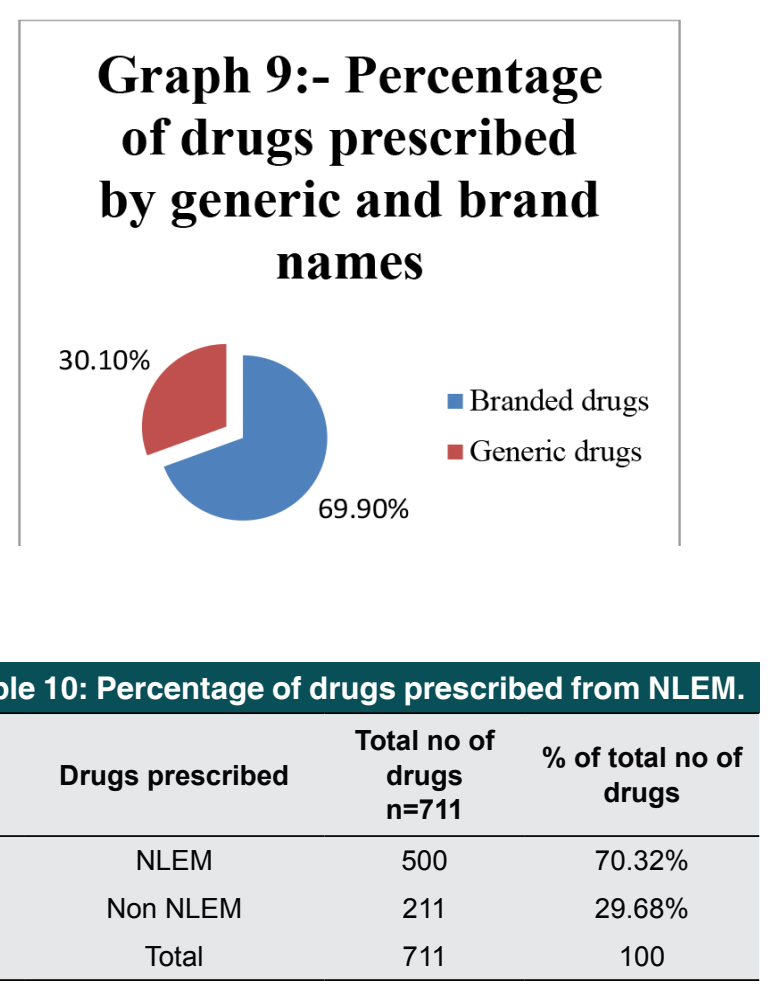

\section{Graph 10:-Percentage of drugs prescribed from NLEM}

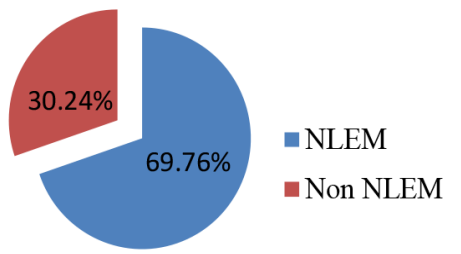

prescriptions by WHO core prescribing indicators. The results reveal that the average number of drugs per prescription was 4.98 which indicate polypharmacy. $69.36 \%$ drugs were prescribed by brand name, 30.64\% drugs prescribed by generic name which shows dominance of pharmaceutical companies. $69.76 \%$ drugs were prescribed from NELM, physicians should be motivated to prescribe more form NELM.

A total of 134 paediatric in-patients were enrolled into the study by considering study criteria. 711 prescriptions were issued to them, same were collected and analysed.

The gender distribution of the enrolled patients reveals that, there were more number of male patients $(55.22 \%)$ when compared with female patients (44.78\%) our results are similar to the study carried out by Sushma M et al. ${ }^{7}$ and Ashraf $\mathrm{H}$ et al. ${ }^{8}$ which indicated higher hospitalisation rates in males when compared to females.

The age distribution of the study subjects reveals that, there were more number of children $(90.29 \%)$ when compared with infants $(9.71 \%)$ our results comply with the study results of Palikhe $\mathrm{N}$ et al. ${ }^{9}$ and Sunil $\mathrm{K}$ et al. ${ }^{10}$

Our results shown that, the total duration of hospital stay was 607 days with an average stay of 5.7 days per patient. Majority of the patients (32.28\%) stayed for 5 days. The maximum stay duration was 11 days $(1.82 \%)$. The study conducted by Venkateshwaramurthy $\mathrm{N}$ et al. ${ }^{11}$ shown an average stay of $4 \pm 2$ days per patient which is similar to our finding.

Among 134 paediatric patients case sheets, the prescribers mentioned weight of the patient in $108(80.59 \%)$ case sheets. Whereas prescribers failed to mention weight of the patient in $26(19.41 \%)$. Failure to mention the weight in the pediatric prescriptions needs to be addressed as the weight of the patient plays a vital role in choosing the appropriate dose.

Our study reveals that, the majority of the paediatric 
patients were diagnosed with respiratory tract infections $(34.32 \%)$ followed by gastrointestinal disorders $(17.91 \%)$ fever (13.44\%) and haematological disorders (11.19\%). The study conducted by Venkateswaramurthy. $\mathrm{N}$ et al. ${ }^{11}$ also shows the high prevalence rates of respiratory tract infections with $39.6 \%$ and gastrointestinal disorder with $17.9 \%$

The results of therapeutic class of drugs reveals that, the antibiotics were the highly prescribed therapeutic class of drugs $(39.52 \%)$ followed by multivitamins $(17.51 \%)$. The study carried out by Sharad G et al. ${ }^{1}$ and Ashraf $\mathrm{H}$ et al. ${ }^{8}$ showed that the highest prescribed therapeutic class of drug were antibiotics with $37.2 \%$ and $43.19 \%$ respectively which is almost similar to our findings indicating the most frequently prescribed drugs were antibiotics. The excessive and inappropriate use of antibiotics leads to antibiotic resistance hence there is a need to develop antibiotic prescribing guidelines at the study site.

Among the antibiotics prescribed cephalosporins were the highly prescribed antibiotics $(32.74 \%)$ followed by penicillins $(28.46 \%)$ and aminoglycosides $(24.55 \%)$. A study conducted by Sunil K et al. ${ }^{10}$ revealed that the most preferred antibiotics were cephalosporins $(28.79 \%)$ followed by penicillins $(23.82 \%)$ and a similar study conducted by Choudhary $\mathrm{D}$ and Bezbaruah $\mathrm{B}^{12}$ shown that the preferred antibiotics were cephalosporins $(41.50 \%)$ followed by penicillins $(35.50 \%)$. The above findings almost comply with our study results.

Our study reveals that, parentral $(57.18 \%)$ was most preferred route of administration over the oral route (42.82), which increases the cost of the therapy. These findings comply with the study result of Sunil $\mathrm{k}$ et al..$^{10}$ and Ansam S et al. ${ }^{13}$

The prescriptions were analysed by using WHO prescribing indicators. The average number of drugs per encounter was 4.98, which is almost similar to the study findings of Shankar P et al. ${ }^{14}$ with an average of 5.5. The polypharmacy leads to increased risk of drug interaction, cost and errors of prescribing. Hence it is preferable to keep the number of drugs per prescription as low as possible at study site.Among 711 drugs prescribed majority of the drugs were prescribed by brand names $(69.36 \%)$ followed by generic names (30.64\%). The study conducted by Sarkar $\mathrm{P}$ et al. ${ }^{15}$ shown that $75.6 \%$ drugs were prescribed by brand names followed by $24.4 \%$ generic names, which justify our results or findings. The low generic prescription reflects the influence of pharmaceutical companies.

Among 1214 encounters, the antibiotics were prescribed in 1155 encounters $(95.14 \%)$. A study conducted by Anuja A et al. ${ }^{16}$ shown that in $79 \%$ encounters antibiotics were prescribed, which shows the high prescribing trend of antibiotics. In our study in 1092 (89.95\%) encounters the injections were prescribed, whereas study conducted by Balushi $\mathrm{K}$ et al. ${ }^{3}$ shown that the percentage of encounter with an injection prescribed was $37.92 \%$.

The percentage of drugs prescribed from NELM $(69.76 \%)$ reveals that the majority of drugs were prescribed from NLEM. Still there is a need to motivate the prescribers to prescribe from NELM. The essential drugs offers many advantages including cost safety and effectiveness.

At the outset in the study site, the parentral route of administration was most preferred, which increases the cost of therapy. Weight of the pediatric patients was not mentioned in few cases, mentioning the weight is of great importance as it plays an important role in calculating the dose.

\section{CONCLUSION}

Failure to mention the weight in the pediatric prescriptions needs to be addressed as the weight of the patient plays a vital role in choosing the appropriate dose. The recovery rate was affected due to not mentioning the weight of the patient which adds to the financial burden on the patient.

Prevalence rate of respiratory tract infections was high, so there is a need to educate the parents about the various factors like pollution, dust, climatic conditions, maintenance of hygiene, dense population which are the most common factors for causing RTI.

The study reveals that the usage of antibiotic is high at the study site when compared with the WHO recommended $20 \%$ antibiotic use. Overuse of antibiotics can lead to antibiotic resistance which is becoming one of the threats to the public's health.

The average no of drugs per prescription was high when compared with the recommendation of WHO (1.6-1.8\%). Polypharmacy can unnecessarily increase the cost of treatment and put an additional burden on already exhausted health-care system. Polypharmacy has been reported to be the one of the causes of ADRs in children, which can further add to the cost of therapy

In a nutshell, at the study site the irrational use of drug was observed, hence our study suggests that strategies to control the irrational use of drugs should be implemented 
and the guidelines for the treatment of paediatrics patients should be framed and implemented. In this regard the pharmacist can play a vital role by educating the prescribers to promote the rational use of drug.

\section{ACKNOWLEDGEMENT}

We would like to thank HOD, Department of Paediatrics for their support and encouragement throughout the study.

\section{CONFLICT OF INTEREST}

The authors declare no conflict of interest.

\section{ABBREVIATIONS}

WHO: World Health Organization; NLEM: National List of Essential Medicines; IV: Intravenous; IM: Intramuscular; UTI: Urinary Tract Infection; RTI: Respiratory Tract Infection; PEM: Protien Energy Malnutrition; CNS: Central Nervous System; HIV: Human Acquired Immunodeficiency Virus; ICU: Intensive Care Unit; UTI: Urinary Tract Infection.

\section{SUMMARY}

Strength of the study: The present study reviews the present prescribing trends at the study site. The study can be utilized as a tool by the researchers in order to carry out the same at larger scale.

Limitations of the study: The study was conducted on a small sample size therefore larger sample size would give a better outcome.

Controversies: No controversies were raised during the study.
Future study: The study was conducted on a small sample size, same study can be conducted on larger scale with large sample size.

\section{REFERENCES}

1. Sharad G, Umesh P, Mamta V, Sanjay G, Ashutosh C. Drug prescription pattern in a paediatric outpatient department in a teaching hospital in central. India Int J Pharm Sci. 2012;17(2):42-5.

2. Dinesh K, Padmasahani L, Vasanta J, Veera R, Sudhakar P, Uma M, et al. Drug prescribing pattern among paediatricians in an outpatient department of tertiary care teaching hospital. Ind J Pharm Pract. 2011;4(2):64-8.

3. Balushi K, Sawafi L, Ghafri F, Zakwani A. Drug utilization pattern in an omani pediatric population. J Basic Cli Pharm. 2013;4(3):68-71.

4. Hogerziel H, Ross-Degan D. Field tests for rational drug use in twelve developing countries. Lancet. 1993;342(8884):1408-10.

5. WHO: How to investigate drug use in health facilities: selected drug use indicators. Geneva. 1993. Available at http://www.biomedcentral.com

6. Laing $\mathrm{R}$, Hogerziel $\mathrm{H}$. Ten recommendations to improve use of medicines in developing countries. Health Policy Plan. 2001;16(1):13-20.

7. Sushma M, Astha S, Ayesha R, Jayanthi C. Prescribing pattern in paediatric urinary tract infections at a tertiary care centre. J Chem Pharm Res. 2012;4(6):3201.

8. Ashraf $\mathrm{H}$, Handa S, Khan N. Prescribing pattern of drug in padiatric outpatient department of child care center in Moradabad city. Int J Pharm Sci Rev And Res. 2010;3(2):1.

9. Palikhe N. Prescribing pattern of antibiotics in paediatric hospital of Kathmandu Valley. Med J. 2004;(2):6-12.

10. Sunil K, Punam S, Madhuri K. Patterns of prescription and drug dispensing. Ind J Pediatr. 2005;72(2):117.

11. Venkateswaramurthy $N$, Murali $R$, Sampath $K$. The Study of Drug Utilization Pattern In Pediatric Patients. Int J Pharm And Sci. 2013;5(3):1491.

12. Choudhury D, Bezbaruah B. Antibiotic prescriptions pattern in paediatric inpatient department gauhati medical college and hospital, Guwahati. J Applied Pharm Sci. 2013;3(08):144-8.

13. Ansam S, Ghada A, Laila A, Waleed S, Rowa A, Nidal J, et al. Pattern of parenteral antimicrobial prescription among pediatric patients in al-watani governmental hospital in Palestine. An - Najah Univ J Res Sci. 2006;20:197-8.

14. Shankar P, Upadhay D, Subish B. Prescribing patterns among paediatric inpatients teaching hospital in Western Nepal. Singapore Med J. 2006;47(4):261-5.

15. Sarkar C, Das B. Prescribing trends in a teaching hospital in Western Nepal. J Nepalgunj Med College. 2002;2:4-5.

16. Anuja A, Subhash B, Prakash R. Prescription analysis of pediatric outpatient practice in Nagpur. City Int J Pharm Sci And Res. 2010;35(1):70. 